\title{
Ureteric injuries following laparoscopic hysterectomy: A report of three cases
}

\begin{abstract}
R.B. Parkar, MBBS, MMed, Consultant Obstetrician and Gynaecologist, Y. Patel, MBBS, MD, Consultant Obstetrician and Gynaecologist and Aruna Chudasama, MBBS, MD, Consultant Obstetrician and Gynaecologist
\end{abstract}

Corresponding author: Dr. R.B. Parkar, P.O. Box 520, Sarit Centre, 00606, Nairobi, Kenya

\section{Summary}

The laparoscopic approach to uterine disorders requires greater skills and expertise but may be associated with longer operating times, and complications when compared to the abdominal approaches. Of the potential complications during laparoscopic hysterectomies, ureteric injures are of a major concern. We report on three ureteric injuries encountered during total laparoscopic hysterectomy and review the relevant literature.

\section{Introduction}

Abdominal hysterectomy remains the most prevalent and invasive form of management of uterine disorders representing $57 \%$ of all hysterectomies (1). Although the vaginal route has been recommended in women with benign disease and pelvic relaxation, and forms $29.2 \%$ of all hysterectomies in the United States, laparoscopic hysterectomy is now gaining ground (1).

The incidence of ureteric injuries following hysterectomy varies. Raut et al in 1991 documented 12 ureteric injuries (1.34\%) following 892 gynaecological procedures (2) while Nawaz et al reported a rate of $0.6 \%$ following gynaecological procedures over a 20 year period at the Aga Khan University Hospital, Karachi (2). In a retrospective analysis at a major Sydney teaching hospital, Asian et al reported an overall risk of ureteric injury for all methods of hysterectomy to be $0.44 \%$ (4). The injuries are more apparent in cases with any previous pelvic surgery, presence of endometriosis, pelvic inflammatory disease, previous radiation, pelvic malignancies, adhesions from other causes or even in cases of anatomic variations or distorted anatomy (5).

The mechanism of ureteric injuries during operative procedures include crushing from a misplaced clamp, suture ligation, partial or complete primary transection, angulation, avulsion or ischaemic necrosis following electrocoagulation. Most iatrogenic ureteric injuries are noticed postoperatively (2-4).

In Kenya, no data on the incidence of ureteric injures following gynaecological procedures have been published. We present three cases following laparoscopic hysterectomy.

\section{Case reports}

Three cases of ureteric injures were encountered between 2000 and 2009. The cases followed total laparoscopic hysterectomy. Of the three, two injuries were detected intra-operatively at the time of bladder reflection. A consultant urologist was called in both cases and primary repair with end to end anastomosis and stenting undertaken via laparotomies. The third patient presented on the $4^{\text {th }}$ postoperative day with abdominal pain 
and distension. An IVU done confirmed an intraperitoneal leak of urine. A Urologist then performed a right ureteroneocystostomy with a psoas bladder hitch, through a laparotomy. All three injuries occurred in patients with previous caesarian sections. Two of the uteri weighed between 200-300gm while the third weighed 300$400 \mathrm{~g}$. The right ureter was involved in all three cases and the level of injury was the distal ureter at or just above the pelvic brim close to the uterine vessels and uterosacral ligaments.

\section{Discussion}

During the period May 2000 to March, 2009, we had performed 536 laparoscopic hysterectomies including 234 laparoscopic assisted vaginal hysterectomies, 54 laparoscopic subtotal hysterectomies and 248 total laparoscopic hysterectomies. This represented a rate of ureteric injury of $0.54 \%$, a figure within the incidence rates reported in previous studies (6). This rate is also not any higher than rates of $0.5 \%$ to $1.5 \%$ reported for traditional open gynaecological surgery $(7-10)$.

All the injuries in this study were recorded for the right ureter and in patients with preoperative risk connected with past history of adhesiogenous surgery. These results are also in keeping with previous observations $(10,11)$.

One of the characteristics of ureteric complications following laparoscopic surgery is that they are more often diagnosed post-operatively. According to previous reviews, ureteric injury was recognised intra operatively in only $8.6 \%$, post operatively in $70 \%$ and in $21.4 \%$ of cases, the timing was not specified $(12,13)$. Contrary to this, we identified two of the three injuries intraoperatively in our series.

Routine cystoscopy during laparoscopic surgery is not a guarantee to the recognition of all ureteric injuries but its value is found to be more in cases where the uterine vessel haemostasis was secured by sutures instead of bipolar cauterization. Cystoscopy after intravenous injection of indigo carmine is found useful in ruling out ureteral injury following surgery involving difficult laparoscopic hysterectomies $(7,14,15)$.

All the three injuries occurred in patients who underwent total laparoscopic hysterectomy and none in the subtotal hysterectomy or laparoscopic assisted vaginal hysterectomy. The explanation seems obvious as there is close proximity of the distal ureter to the cervix, anterior vaginal wall and the uterosacral ligaments.

Complications have also been studied according to the type of hospital in which the procedure was performed. The incidence of ureteric injury during laparoscopic hysterectomy is maximum in local hospitals $(2.2 \%)$, moderate in central hospitals $(1.1 \%)$, and least in university teaching hospitals, $(0.6 \%)$ (14). The rates of these complications decrease steadily as the experience of the primary surgeon increased over time (15-18 ). The repair of ureteric injury was via laparotomy in $61.4 \%$ of cases in a review by Ostrzenski et al. With improving minimal access surgery skills, repair of the ureter could be undertaken by laparoscopic approach (6). In out series, all repairs were undertaken through Laparotomies.

In conclusion, laparoscopic hysterectomy is a feasible technique with various advantages. It is however necessary for the indications to be perfect, and for the laparoscopic pelvic surgeon to be fully conversant with the detailed anatomy of the pelvis and its distortions.

\section{Acknowledgement}

To the Aga Khan University Hospital, Nairobi and The Mombasa Hospital, Mombasa, colleagues and theatre staff and to the patients for making this publication a reality.

\section{References}

1. Agency for Healthcare Research and Quality Trend in Hysterectomies performed in the United States has remained flat for 1990 to 1997, Press 31, 2002, Rockville M.D. 
2. Raut V., Shrivastava A., Nandanwar S., et al. Urological injuries during obstetric and gynaecological surgical procedures. J. Postgrad. Med. 1991; 37: 21.

3. Nawaz F.H., Khan Z.E. and Rizvi J. Urinary tract injuries during Obstetric \& Gynaecological surgical procedures at the Aga Khan University Hospital, Karachi, Pakistan: A 20 year review. Urol. Int. 2007; 78: 106-111.

4. Asian P., Brooks A., Drummond M. et al. Incidence and management of gynaecological related ureteric injuries. Austr. \& New Zealand Obstet. Gynaecol. 2008; 39(2): 178-181.

5. Al-Awadi K., Kehinde E.O., Al - Hunayan Al., et al. Iatrogenic ureteric injuries: incidence, aetiological factors and effect of early management on subsequent outcomes. Int. Urol. Nephrol. 2005; 37(2): 235-241.

6. Ostrzenski A., Radolinski B., Ostrzenska K.M., et al. A review of laparoscopic ureteral injury in pelvic surgery. Obstet. Gynecol. Surv. 2003; 58 (12): 794799.

7. Harkki- Siren P., Sjoberg J., Makinen J., et al. Finnish national register of laparoscopic hysterectomies: A review and complications of 1165 operations. Amer. J. Obstet. Gynecol. 1997; 176: 118-122.

8. Vakili B., Chesson R.R., Kyle B.L., et al. The incidence of urinary tract injury during Hysterectomy; a prospective analysis based on universal cystoscopy. Amer. J. Obstet. Gynecol. 2005; 192: 1599-1604.

9. Dorairajan G., Rani P.R., Habeebullah S. et al. Urological injuries during hysterectomies: a 6-year review. J. Obstet. Gynaecol.Res. 2004; 30: 430-435.
10. Wattiez A., Soriano D., Cohen S.B., et al. The learning curve of total laparoscopic hysterectomy: comparative analysis of 1647 cases. J. Amer. Assoc. Gynecol. Laparosc. 2002; 9: 339-345.

11. Carley M.E., McIntire D., Carley J.M. et al. Incidence, risk factors and morbidity of unintended bladder or ureter injury during hysterectomy. Int. Urologynecol. J. Pelvic Floor Dysfuct. 2002; 13: 18-21.

12. Oh Br, Kwon D.D., Park K.S., et al. Late presentation of ureteral injury after laparoscopic surgery. Obstet Gynecol. 2000; 95:337-339.

13. Saidi M.H., Sadler R.K., Vancaillie T.G., et al. Diagnosis and management of serious urinary complications after major operative laparoscopy. Obstet. Gynecol. 1996; 87: 272-276.

14. Dandolu V., Mathai E., Chatwani A., et al. Accuracy of cystoscopy in the diagnosis of ureteral injury in benign gynecologic surgery. Int. Urogynecol. J. Pelvic Floor Dysfunct. 2003; 14: 427-431.

15. Ribeiro S., Reich H., Rosenberg J., et al. The value of intra-operative cystoscopy at the time of laparoscopic hysterectomy. Hum. Reprod. 1999; 14: 1727-1729.

16. Phipps J.H. and Tyrrell N.J. Transilluminating ureteric stents for preventing operative ureteric damage. Brit. J. Obstet. Gynaecol. 1992; 99: 81.

17. Harkki-siren P., Sjoberg J., Turki T. Major complications of laparoscopy; A follow-up Finnish study. Obst. Gynecol. Survey. 1999; 54(10): 632-634.

18. O'shea R.T., Perucco O., Gordon S. et al. Adelaide laparoscopic hysterectomy audit (1991-1998): realistic complications rate. Gynaecol. Endosc. 2000; 9: 369-372. 